\title{
Social capital, social media and the changing patterns of participation in climbing
}

Holland-Smith, David 2017

This is the accepted manuscript of an article published by Taylor \& Francis in Sport in Society on 21 December 2016 available online:

https://dx.doi.org/10.1080/17430437.2016.1269078 


\title{
Social capital, social media and the changing patterns of participation in climbing.
}

\author{
David Holland-Smith
}

Abertay University

\begin{abstract}
This paper draws upon Bourdieu's instrumental perspective on social capital in explaining the process of reproduction and change in the contemporary climbing context. This study investigated how different forms of social media networks have influenced the contemporary climbing culture. This field is a site of contestation between the residual, established and emerging cultures. Increased participation across age and gender seems to reflect the broadening of the middle class social position and this is particularly evident for women and young people. Social media networks reinforced the position and reproductive potential of the middle class in this context. This forms part of a broader five-year study into climbing and mountaineering and draws upon a mixed grounded methodology where the researcher has taken the position of participant observer. Semi structured interviews were conducted with 11 climbers, six males and five females.
\end{abstract}

\section{Introduction}

This study develops Bourdieu's instrumental perspective on social capital in the process of social reproduction and change in the contemporary climbing and mountaineering context and considers the wider cultural, economic and political influences such as globalism, neoliberalism, new patterns of consumption and technological innovation. Bourdieu views the process of social reproduction and change, in the field and habitus complex, as a social site where individuals and groups adopt conscious and unconscious strategies in order to improve and maintain their social status. Whilst change can occur within the field and habitus there are external influences which bring about change through 'hysteresis' (Grenfell, 2008). This paper will evaluate different forms of social capital, found within this context, including face to face as well as virtual interactions (social media) and relationships. A central part of this analysis relates to social class, gender and social positioning. 


\section{Literature overview}

The issue of gender has been covered in the alternative sport literature (Wheaton, 2004; 2010). Examples of different activities have been developed for example, Thorpe (2005) in snowboarding. There are a number of papers covering issues related to climbing. Robinson (2008) and Plate (2007) focus on masculinity and gender subculture. In addition, Dilley and Scranton (2010) have made a contribution to this research by presenting a perspective on women's serious leisure in climbing. Other perspectives explore a feminist phenomenology of climbing (Chisholm, 2008).

Salome (2010) argues that climbing has been traditionally practiced in the natural environment by a small group of white male elites, but are now being undertaken in controlled and artificial settings by a broader demographic of women and young people. 'Indoorisation' (Van Bottenbur\& Salome, 2010) constitutes an emerging form of consumption and constructed authenticity. For Salome (2010) it is technology that has created the opportunity for the development of artificial indoor environments. In this context, authenticity has multiple meanings, but it is suggested that this can be understood as a process of 'looking back' to former period where such practices were associated with romanticised and idealised notions of climbers' relationship with the environment (see Beedie,2008; Lewis,2000; Humberstone, 2011). Commodification has created tensions regarding the authenticity of indoor climbing between traditionalists and youth culture (Honea, 2004).

West and Allin (2010) explored the relationship between risk taking in relation to climbing identities. Holland-Smith and Olivier (2013) present an insider perspective on elite Scottish adventure climbers and the social construction of risk discourses related to climbing identities. Bogardus (2012) examines commodification and the media in the construction of internal status hierarchies and how climbers define informal rules played out through inter group conflict over the legitimacy of practices that reduce risk. Bogardus presents a complex and 
nuanced perspective of social change within the climbing and how climbers use status and power. Haywood (2006) explores the tension between the technical and performative aspects of climbing (Body technique) and situations that are high risk ('Bottle' Spiritedness or thumos) in the context of gritstone climbing in the late 1990s.

Bunn (2015) investigates, in the context of climbing, what initially draws people in to risk taking and the development of dispositions. He argues that these dispositions are developed through the gradual exposure in associated fields of activity such as other outdoor activities that share similar dispositional qualities. Through exposure participants gradually come to appreciate the logic of adventure practices in climbing. Bunn (2015) draws upon Bourdieu's concepts of doxa and illusio (Bourdieu, 1990) to explain this process of socialisation.

Holland-Smith (2015) investigated how formative experiences have influenced climber's engagement with climbing. This paper explores gender and class reproduction from a Bourdieuan perspective. The analysis brings together the broad concepts of social class and gender and draws upon Bourdieu's masculine domination thesis (Bourdieu, 2001) and various feminist perspectives to understand gender and social positioning as well as the process of social change, agency and identity transformation.

The purpose of this study is to explore the specific nature and forms of social capital that are evident in the modern climbing context and how these contribute to social reproduction, the maintenance of social status, and access to resources and opportunities. This study complements existing literature related to climbing and expands on some of the perspectives outlined in the literature review. Field theory is used as a means of mapping social space but also it becomes possible to examine how social change, agency and identity transformations are related to power and structural relations and how these are played out in this context. This framework is useful because it brings together the structural and phenomenological perspectives into a coherent, method of social enquiry (Bourdieu \& Wacquant, 1992).

\section{Social Capital}


According to $\mathrm{Li}(2015)$ the broad concept of social capital has captured the imagination of social scientists and policy makers across a range of different areas and they have tended to work in one of two traditions which can be defined in terms of the civic (Putnam, 1993, 2000, 2004; Coleman, 1990) or instrumental dimensions of social capital (Bourdieu 1984, 1986). These dimensions have drawn upon specific theoretical perspectives and domains of analysis.

Social capital is defined as the resources available to people through their social connections and interactions (Putnam, 1993, 2004). It is acknowledged that social networks have value, economically and socially (Bourdieu, 1984; Coleman, 1990; Putman, 1993, 1995a, 1995b, 2004). Individuals and groups who have large and diverse networks have more social capital than those with small and less diverse networks and if utilised may bring about a range of benefits and opportunities to those included in these networks (Adler \& Kwon 2002; Blackshaw \& Long, 2005; Coalter, 2007; Kay \& Bradbury, 2009; Ottesen, Jeppesen \& Krustrup, 2010).

According to Putnam's perspective, the civic and functional aspects are emphasised in enabling individuals and groups to develop norms, trust and reciprocity which are deemed to be a prerequisite for engagement in social collective activities it also facilitates their access to resources, information and opportunities. In contrast, Bourdieu (1986) views social capital as part of the strategies for social reproduction which predominantly serve instrumental purposes. In terms of the domain of analysis this perspective focuses on the processes of cultural reproduction at the individual and group level, where capital(s) are the possession of individuals and groups and can be utilised in the pursuit of their own goals. Social capital has to be mobilised in order to gain access to these resources and this is particularly relevant in the context of this study.

According to Bourdieu (1999) social spaces and relationships (fields) such as those found within sport, are characterised by conscious and unconscious manoeuvers, where actors develop strategies to and maintain the accumulation and hierarchies of capitals in all their forms (Symbolic, cultural and economic) in order to improve and maintain positions, status 
and power which results in exclusivity (Whittaker \& Holland-Smith, 2014). Cultural capital specifically refers to social and symbolic assets such as dress, the way a person speaks, their education, cultural artefacts and dispositions (Habitus). Cultural capital can enable access to other forms of capital via the exchange process where cultural capital is transformed into economic capital and vice versa.

Movement into and across different social fields is facilitated by particular forms of cultural capital. Social capital and social networks starts with the family and can act as a catalyst for easing social mobility within new and existing social networks and even across different social fields such as education, work and adventure sports (Holland-Smith, 2015). It is argued that the middle class (family) invests in sociability and the cultivation of habitus through which they acquire particular forms of credentials, capitals and social networks and there by gain access to privileged social positions (Bourdieu, 1986). Fletcher (2008) indicates that climbing and associated adventure sports fields have a high degree of 'ontological complicity' with the middle class habitus which lubricates their entry and participation in such social fields. Habitus is concerned with relational conditioning where individuals absorb the objective social structures and relationships of the specific context into a set of both mental (cognitive) and physical dispositions (somatised body). Ontological complicity relates to the relationship that exists between the habitus and the field. The habitus is produced in the field as a direct reflection of the objective social relationships that exist in that field and also in the habitus of individuals who inhabit that field. According to Bourdieu and Wacquant (1992) there is a twoway interaction between the individual, their habitus and the habitus of the social field. This is what Bourdieu refers to as 'ontological complicity'. So when an individual from a particular social position or set of objective social conditions enters or encounters another field with a similar habitus or objective social relations they become ontologically complicit. Where there is a lack of 'ontological complicity' practices generated by the habitus are mismatched with the current social space and are indicative of having their origins in a different objective social conditions and relations. 
The professional middle class tend to work in fields that require higher educational qualifications, engage in mental labour, that is relatively well paid, have a high degree of personal autonomy and self-direction. It is argued by Fletcher (2008) that adventure activities are closely associated with professional middle class values and share a number of the same core dispositions. In this context, social networks are seen as being instrumental in facilitating participation and status amongst the members of this social network (middle class professionals) and have a potentially significant role in limiting social mobility and access to those who are outside this contextual community (Skinner et al, 2008; Hartmann \& Kwauk, 2011; Kelly, 2011). High levels of ontological complicity between the middle class habitus and the adventure habitus facilitates social mobility of those who belong to the middle classes and creates barriers for those from different social positions and objective social relations.

It has been argued that instead of encouraging and promoting inclusion, attempts to integrate people from outside these sports networks has brought about a tightening of the exclusive ties and bonds and inward looking associations (Bourdieu, 1999; Paik, NavarreJackson, 2011; Skinner, Zakus \& Cowell, 2008; Stemple, 2006; Whittaker \& Holland-Smith, 2014). This has been referred to as the dark side of social capital (Whittaker \& Holland-Smith, 2014).

Adventure sports has become a general term for a range of sport activities such as kayaking, climbing mountaineering, skiing, snowboarding, surfing which take place in the natural environment. This covers a range of diverse forms of activity. Traditional forms of adventure sport required the investment of resources to acquire the skills, dispositions and capitals. According to Wheaton (2004) such lifestyle sports are integrated with personal factors such as careers, families, relationships, lifespan and consumption and are linked to specific personal identities.

The development of adventure sports has been driven by commercial interest, new emerging patterns of consumption and broader cultural developments under late modernity (Wheaton, 2010). The development of climbing walls in the post 1980 s coincided with the 
parallel development of new forms of media, information technology and social media. This changing context and culture is significant for the participation of the middle class (families, women and young people) (Breivik, 2010; Wheaton, 2010). These new forms of adventure experience became more visible and available to a mass market consumer. The traditional characteristics of climbing and mountaineering were replaced by new forms of practice, participation and engagement.

Salome has noted that the development of indoor venues such as climbing walls marked a paradoxical development in adventure sports. These new forms of adventure sports emerged out of the traditional forms of climbing and mountaineering which were undertaken in the natural environment (Beedie, 2008; Brown, 2009). These new forms of traditional activities retained some of the meanings, characteristics and cultural values which made them recognisable as forms of adventure sport (Salome \& Van Bottenburg, 2012). Whilst being associated with climbing and mountaineering, they have lacked authenticity, status and legitimacy as far as the traditional climbing and mountaineering community was concerned (Donnelly, 2006).

\section{Methodology}

Participants were recruited through the Scottish Mountaineer (Scottish Mountaineering Council and British Mountaineering Council), posters in climbing walls and contacts through the Association of Mountaineering Instructors (AMI). This group were self-selecting and determined. The participants at the time of this study were still active in a range of different climbing disciplines and used climbing walls on a regular basis. All lived and worked in various locations in Scotland and were professionally employed or trained or in full time higher education. The participants were (6) males between the age of (20) and (55) and (5) females between the age of (19) and (54) years.

\section{Procedures.}


Ethical approval was granted by the university's ethics committee before data was collected. The participants gave informed consent to the research before the interviews were undertaken. They were made aware that their involvement was voluntary and they could withdraw at any time without giving a reason or justification and all data would remain confidential, anonymous and used for publication. This research employed a grounded research paradigm (Glaser \& Strauss, 1976) which explored the issues related to their climbing experiences, climbing relationships and social networks in contemporary cultural and structural climbing settings (Roberts, 2002) as well as the connection with the participant's past and present experiences.

Data was collected using semi structured interviews over a period of five years as part of a broader research project related to climbing and mountaineering. Semi-structured interviews were used because they produce rich in depth data required in addressing these research questions. The interviews were conducted in a variety of locations including the participants' homes, work locations and at climbing venues (indoor climbing walls and sport climbing crags). The interviews lasted for between 1 and 2 hours and were audio taped and transcribed. The interviews covered a wide range of climbing themes as a guide for the interviews. Specific emphasis was placed on participation, media and climbing, climbing partnerships and relationships as well as use of social media. The interviews were recorded and transcribed verbatim and checked for accuracy by the researcher and the participants. This interview data was thematically analysed. An inductive, line by line, analysis was applied to identify individual units of meaning. These units of meaning were organised as core themes as other sub-themes were identified (Van Manen, 1997) and links were made with various theoretical and empirical perspectives.

The approach adopted followed an emergent process where themes and issues were probed and explored allowing the participants and researcher to explore these subjective realities in their own language and terms (Dowling \& Naess, 1996; Jones, Armour \& Potrac, 2003). In this context the interviewer became an active listener and explored the emerging 
issues, interpretations, recollections, and connections with the participants through probing questions and asking for illustrations and examples. This was inductive (Glaser \& Strauss 1976) and 'reflexive' in nature (Hammersley \& Atkinson, 1983).

The researcher identified himself as an experienced adventure climber with over 30 years' experience. The researcher took the position of an active participant observer and attended climbing venues regularly as part of his active engagement in the research. Data was collected and recorded retrospectively in a diary. This included reflective observations and tentative interpretation related to the phenomena being investigated. These were subsequently refined as insights and understandings developed. This was a continuing process over a five-year period of the broader research project. Some of the data took an autobiographical perspective (Tenni, Smyth \& Boucher, 2003) and drew directly on the researcher's personal narratives and experiences. This provided a way on validating and interpreting events, phenomena being observed as well as data obtained through the semi structured interviews.

The researcher acknowledged that he shared a similar subject position (insider) to the participants which has enabled him to ask appropriate probing questions and to gain insights that would not be possible to an outsider (Rinehart, 2002). This inside position created some limitations on the interpretations being presented with regard to biasing, making assumptions and unexplored presuppositions. In order to gain greater trustworthiness in the data and interpretations presented these were discussed with a critical friend, with some of the participants and an impartial outside perspective (Sparkes, 1998). Before the initial interviews were carried out bracketing interviews were conducted in order to identify any issues that might bias the data and interview process (Tufford \& Newman, 2010). A further process of member checking was carried out with some of the participants on the final versions of the transcripts and interpretations presented.

\section{Results and Discussion}


Six main themes emerged from the interviews. These included: Social relations, positioning and capital; Social media and social capital; Social and performative relationships; Resources and social networks; Youth culture and social media; and Hysteresis, reproduction and social change.

\section{Social relations, positioning and capital}

Social involvement is about maintaining, developing and acquiring social networks, cultivation of capitals, habitus and social positioning. This sociability is illustrated by James. He makes a clear distinction between the social side of being in the climbing context and the activity of climbing:

'It can be really social or it can be really individual, it can be whatever you want it to be depending on what type of thing you choose to do. If I were to climb in Glasgow (climbing wall) it takes about 40 minutes to actually start climbing because you say hello to everyone you know so it can be more social in that sense'.

Indoor climbing contexts comprise of resource-rich social networks. According to Wheaton (2010), participants and consumers have a broad range of different interests and experiences and their social positioning can be determined in terms of being 'insiders', 'outsiders', 'hard-core' and 'grazers'. 'Outsiders' and 'grazers' can be distinguished through their capitals, practices and habitus in terms of how they relate to the climbing habitus in terms of their ontological complicity (Bourdieu and Waquant,1992). For 'Outsiders' and 'grazers' there is a mismatch between their habitus and this field - which is indicative of different objective social relations and this determines and signals their status and positioning. 'Insiders', 'outsiders', 'hard-core' and 'grazers' can be identified through the specific way they dress, style of climbing, technical skill levels and body shape (somatised body). 
James is positioned as a 'hard-core' insider in that he sees himself, and is seen by others, as being a committed practitioner who is familiar with the cultures of climbing, and has spent considerable time, money and resources developing his skills.

From field observations the relationship between insiders, outsiders,' hard-core' and 'grazers' becomes more clear. This is expressed through specific, recognisable styles, bodily dispositions, expressions and attitudes within the climbing context. For example, two climbers who could clearly be identified as outsiders / grazers because they were wearing football tops and shorts, they climbed using strength and power and their bodies were muscular and bulky. They stood out in contrast to the lean, sinuous bodies of other climbers (hard-core insiders), who climbed with grace, poise, balance and economy. (Field Notes/ observation).

The process of somatisation according to Brown (2006) is concerned with the process of embedding these social relations into the body. These relations are historically and culturally situated but become embedded in the biological body as signifiers of these relationships and constructions. Through specific sport practices, can lead to profound transformations of both the subjective and objective experience of the body. The distinctive way the climbers ('Insiders', 'outsiders', 'hard-core' and 'grazers') use and train their bodies takes on an embodied from and is indicative of their social positioning.

\section{Social Media and Social Capital}

There have emerged a number of views regarding the impact of social media on the development of social capital, in different forms and how this might generate or accrue particular affordances (Williams, 2006). It is possible to build up a personal climbing profile through an online logbook of personal climbing activities including types of climbing, locations, technical standards and experience. The use of social media platforms is used as a medium to cultivate, demonstrate and maintain cultural capital, status and social positioning within the 
climbing community. However, under certain conditions such forms of social media capital could build homogeneous networks at the expense of diversity and vertical integration. This is especially evident where members of a social media network have particular forms of cultural capital related to their middle class social positioning as well as specific forms of capital related to social media such as structural, cognitive and relational capitals (Valenzuela, 2009; Donath \& Boyd, 2004; Wasko \& Faraj, 2005).

The type of social capital generated by social media could be related to what has become known as tie strength (Gilbert \& Karahalios, 2009). Stronger tie strengths are characterised by being constructed amongst trusted people you like and are integrated and overlapping. The people who belong to such networks are usually highly educated, professional and metropolitan who communicate through many different channels. The implications of tie strength are deemed to be important when assessing and modelling the formation of bonded social networks in social media and the process of social reproduction (Granovetta, 1973).

This is demonstrated by James. He clearly recognised the importance of social media for promoting his own climbing and invested a lot of time and resources in developing his own website:

'I had to set up my own website, I had a lot of work to do on it and that's what I did. I literally spent $18 / 19$ hours a day for most of the summer and it caused all sorts of problems but I couldn't help myself doing it and I found it really hard'.

'Internet reflects completely what people are interested in because it's generated by those people. It's so much more effective, you know it's great because it means that every one is the media, anyone who has anything to say can just say it on a website and opinions about everything to do with the sport: whether it should be kept as a small niche, whether it should be mainstream, what the ethics should be, what the standards of it should be, everyone can have a say and lots of people do. Climbing websites, they're just absolutely massive for me. I started 
a climbing website about a year ago and it just absolutely overwhelmed me by the number of people who came to it'.

A number of specific social networks have emerged around climbing and examples of these include: Climb Find, Crag Notes and the BMC media centre (meet up.com) and a world rock climbing data base. Crag Notes, Climb Find are used by climbers to keep up with other climbers that are already known to them, that they have made contact with. Contacts are added to through Email addresses and through this climber within the network can find out where people are climbing, times and any other relevant details or information. Such forums are the integration of other related forms of social media such as Twitter (Following) and Facebook (keeping up).

Social media seems to be instrumental in individual and group identity construction (Katz \& Gurevitch, 1974; Ruggiero, 2000) and can fulfil the information needs of users that is recognised as a result of prolonged engagement, where individuals develop mastery of language, practices and culture of the network as well as consolidate their identity and reputation in that network. This is viewed as a factor for strengthening weak ties and promoting collective action (Kenski \& Stroud, 2006).

As in the case of James, individuals with higher levels of structural capital are more likely to sustain collective action and as a result higher levels of cognitive capital develop. There is little evidence to suggest that social media increases the participation and integration of people from outside the contextual community, but seems to support existing relationships, interaction within that community amongst people who have particular forms of high status capitals across the climbing and social media fields.

\section{Social and performative relationships}

Although it is claimed that social media potentially enables climbers to build networks of climbing partners and to update on climbing activities, this is in fundamentally questioned by 
some climbers who were interviewed. Especially the more experienced climbers who engage in traditional, mountaineering and adventure climbing.

Climbing is a social activity that involves climbing with other partners who build strong relationships based on trust, mutual respect and technical competence. The emphasis is placed more on the task related aspects of the relationship. These relationships are built up over a period of time through climbing together. Simon explains that when he started climbing, the climbing community could be defined as a relatively tightly knitted group comprising of a limited number of climbers who knew each other through face to face contact and where they were geographically based:

'When I started getting involved in climbing, I pretty well knew everyone by sight or by name in like the central belt who climbed cos there was a limited number of climbers, you knew them all, you know where they were from. They were either Edinburgh based or Glasgow based climbers, you pretty much knew all the faces, now, no idea, there must be thousands'.

Climbers interviewed reported that they generally do not climb with just anyone that they casually meet at climbing venues or at climbing walls. These substantive relationships are usually formed in other social sites such as the family, education and even work amongst people who have similar social status and credentials. Most importantly these are developed over time and sustained by climbing, the building of trust and mutual validation of competence.

What seems to be emphasised is the task and performative function of these relationships. These relationships are not part of a causal social network nor do they seem to emerge from them. Jane, an experienced climber, reported that her choice of climbing partner was usually male because this facilitated her development and status as a climber. This is illustrative of how she becomes, in Bourdieuan terms, a carrier of capital which has enabled her to accumulate status, and positioning within the climbing context (Bourdieu, 1986). However, Green (1998) emphasises the importance of talking and interpersonal relationships in 
women's leisure experiences and how these relationships are important in the construction of women's identities. These relationships are not just transient but enduring and an important factor that contributes to long-term engagement. This seems to be in contrast to male or masculine values were challenge, mastery and performance are emphasised (Dilley \& Scranton, 2010). For most of the male climbers they emphasised that their social relationships are very much separate from climbing relationships.

This is illustrated by Simon:

'I can't just go and pick someone up off the street or meet them on the internet and think, oh, we'll just go climbing, nah, that's not for me. I like the people I go climbing with. I've climbed with the same guy for 15 years. When we go climbing we're very task orientated, there's not a lot of banter, our climbing trips are not big fun things they're quite driven'.

'We keep in touch but there's not a lot of social interaction in terms of what goes on in our lives, there's an involvement but not the same involvement I've got with other friends it's a different relationship'.

Charles also emphasises that his climbing partnerships have been long established relationships formed in social context outside of climbing with people who have a similar social position as himself:

'I had a strong friendship in college and he taught me to climb and now he comes up here and I take him climbing.'

Sally emphasises that climbing is an important part of her life but she also has a social life outside of climbing and this is a factor that is recognised by both male and female climbers: 
I have another life outside of climbing. I don't mind spending a weekend not being involved in outdoor activities. I like to be sociable with friends and do something different'.

In contrasts, Carol emphasised that outside of her family and work, she has tried, where possible, to integrate her social life with climbing and that most of her friends were climbers.

What seems to be emerging from the interviews, observations and field notes is that social media is used in different ways by different climbing communities. The impact of social media on social capital is contingent on who uses these different forms of technology and how they are used (Hampton, Lee \& Her, 2011). The forms of media have to be social as opposed to passive and also consideration needs to be given to the multiple users, audiences, motives and experiences. Despite the claims that social media parallels traditional settings there is little or no evidence that it is the equivalent to or functions like an actual physical space around which people organise their social relations (Hampton, Lee \& Her, 2011).

\section{Resources and social networks}

The integration of information technology, social media and communication technology into the climbing context has provided a gateway for external cultural values to enter the climbing culture. Apart from climbing there are other associated activities such as: cafes, shops, crèches, retail outlets and business and conference facilities, gyms and health and beauty solons, especially in the larger commercial private and public sector venues such as 'Ratho' in Edinburgh (Scotland). This is illustrative of the capacity to supplement and replace the benefits associated with traditional outdoor climbing venues (Wellman, 2001). Paula clearly identifies the influence of the media and commercial images of climbing and how they have become part of these new climbing contexts:

'The media have got hold of climbing and use it in quite persuasive ways from what l've seen and it's very difficult to distance yourself from these kinds of images'. 
Some of the climbers in this study acknowledged that they a produce images (Photographs and videos) and that these are commercially valuable. Mark is a well-known climber who is able to sell images of climbing and recognises how this has impacted on his own climbing:

'There's so much more of what I do is tied in with the media. You're taking photographs and you suddenly realise that there is a demand for the images that's a by-product of the experience, you no longer just go out and do something you record it. If you record it there's probably someone who's going to want the images and the more adventurous it is the more likely there will be a market for it'.

Modern indoor climbing venues have the brought together a range of different activities related to business, family, entertainment, and retail which constitute diverse networks of interrelated activity. These constitute public spaces that are resource rich and integrate a range of related social fields. These fields are already inhabited by the middle class outside of this context and where they already have the prerequisite capitals, dispositions and social networks. Their class habitus enables these climbers to cross over and enter these different fields and contexts but also enables them to enter this specific climbing context more easily because it is a context that has 'ontological complicity' with their habitus and the habitus of these associated fields. Increased access and participation in climbing, across age and gender, is a reflection of the broadening of the middle class social positioning through horizontal expansion rather than the vertical integration and inclusion of other groups and individuals. The broadening of this demographic is also a reflection of what Wheaton (2004) has called lifestyle sports and how such adventure activities are integrated with personal factors such as careers, families, relationships, lifespan and identity (Tomlinson, Ravenscroft, Wheaton and Gilchrist, 2005).

This is particularly significant for the participation and engagements of the professional middle class (women and some men) that have careers, families and may need to accommodate or integrate their leisure and sport with careers and families. The main areas of many women's lives are work, relationships, domestic and emotional caring labour. As a 
result, women have less access to leisure, time is more limited, fragmented and commonly combined with domestic caring (Deem, 1986; Green et al., 1990; Talbot 1988). According to Scraton (1994) it is impossible to properly understand women's leisure as something separate from the rest of their lives. This is illustrated by Mary, who is an active climber but has to integrate her climbing with her family life:

'Jodie [Daughter] and I will climb on the wall together and James my partner climbs with Peter[Son]. It seems that this is really the only way that I'm able to climb on a regular basis. Most of the time l'm top roping Jodie and looking after her. She's not really strong enough or competent to belay for me'.

The availability of crèches, children's clubs and allocated social spaces such as cafes provide a family friendly context for leisure consumption and the development of social networks. Such social contexts reinforce the central position of the middle class family in these networks and can be viewed as being instrumental in reproducing and maintaining their position. This is particularly significant for young people and children in that they provide a formative structure (Habitus) that influences and shapes their personal, perceptions, and ways of being through which they understand the specific internal logic of this field and habitus. It confers advantage and contributes to the already privileged position of middle class children and young people. Social networks can be maintained and expanded through the use of social media in different contexts such as at work and from home. Social media therefore tends to support and reinforce established networks, but also provides additional access to more diverse networks and social resources (Feld, 1981; Lofland, 1988; Hampton, Lee \& Her, 2011).

\section{Youth Culture and Social Media}

Youth culture is one which has grown up with social and mass media and the integration into the physical infrastructure has enabled subcultural influences to be transported into the climbing culture. It is expressed as different subcultural forms and this reflects the reciprocal 
relationship between youth culture and these sports within a postmodern/ late modern context. Modern climbing culture is expressed as a dynamic lived experience both virtually and materially. Wheaton states: 'Lifestyle sports take multiple and increasingly fragmented forms, drawing on a vast array of narratives that are saturated with ambiguities and contradictions, reflecting the multiple configuration of identity characteristics of cultural practices in late modernity' (Wheaton, 2010: 1060). The lack of formality and emphasis on participation; flexibility; self-determination; and intrinsic motivation fits well with social media and associated forms of social capital. Social media can maintain and sustain weak ties more easily and cheaply than face to face contact, especially where frequency, regency, and communication reciprocation become important for maintaining connection and social capital. (Gilbert \& Karahalios, 2009; Valenzuela, 2009; Donath \& Boyd, 2004).

\section{Hysteresis, reproduction and social change in the climbing field}

The use of social media to share information and disseminate cultural values has influenced the culture of climbing through challenging the domination of the traditional climbing elite who, before the use of social and mass media, held a tighter control over legitimating, defining and disseminating their cultural values through newsletter and traditional publications

such as 'Climber' (Ken Wilson). Social media has contributed in producing a new habitus that is a reflection of their social capital and networks in a resource rich context which enables them to express this through exercising choices, individuality, different forms of identity constructions (which are multiple, fragmented and fluid as well as the capacity to challenge established cultural orthodoxies. The impact of social media and its capacity to democratise the climbing culture is expressed by John:

'I get exasperated with some of the editors who try and steer in the direction that suits their agenda which I guess is what all media publications do to a certain extent. The internet reflects what people are interested in because it's generated by those people'. 
Young climbers are starting to challenge and redefine established ethics and standards of performance within indoor climbing wall context, and this has started to cross over into other outdoor domains. An example of this is the emergence of sport climbing and bolting which has caused some fierce debates and conflict between young climbers and the traditional climbing establishment (Howitt, 2004). The development of sport climbing culture was a product of the practices and culture of indoor climbing and this has provided impetus and motivation for some indoor climbers to venture out to (bolted) local sport climbing venues. Sport climbing has started to become an established form of climbing which did not exist 10 years ago in the Scottish context(Scottish Mountaineering Trust, 2013). The growing popularity of lifestyle sports, forms and spaces are according to Wheaton (2010) related to the broader cultural developments where the expression of identity has become fragmented, multiple, personal, self-reflexive and subject to change which has ultimately brought about a decline in the collective and become increasingly more individualized. This is illustrated by Mike:

\footnotetext{
'On a busy weekend you'll see hundreds of folk and nobody talks to you and it's not bad manners or anything like that it's just purely bulk of numbers and it becomes less informal and less friendly. I think that the people who are going to the walls are urbanised, and they have a different view of life. The emphasis for some people is the sport itself rather than the environment or the venue. You start getting litter at the bottom of crags, you start getting people bawling and shouting at each other, being a bit obnoxious, hogging routes and all sorts of things'.
}

For some of this group of participants they have experienced a new set of cultural practices, values and forms of capital entering and reshaping the field and habitus (Bourdieu, 2006) and this emerging habitus is at odds with the traditional climbing habitus. Contemporary climbing is a diverse activity which is highly nuanced. Indoor climbing walls are used by many different climbing groups ranging from those who wish to try climbing as a one off experience to those who are experienced mountaineers and adventure climbers using them as training venues to 
improve their technical climbing skills. Climbing walls are used by many different climbing groups which generally fall into different factions and practices. The diversity of contemporary climbing is outlined by Mark:

'All the different disciplines of climbing are a sport in their own right. At one end of the spectrum you get traditional adventure climbers and mountaineers and at the other you get those who just climb indoors and wouldn't think about climbing outdoors, maybe even half or more people who climb indoors don't climb outdoors at all. Other areas like sport climbing and bouldering are a lot more mainstream now'

\section{Conclusion}

The integration of information technology, social media and communication technology into the climbing context has provided one gateway for external cultural values to enter the climbing culture. However, this new and emerging habitus of indoor and sport climbing seems to be rooted in the values of established climbing culture. Change and evolution of indoor climbing has been a product of a dialectical process between the residual, established and the emerging cultures (Williams, 1977). In Bourdieuan (Bourdieu, 1999) terms this illustrates the indoor climbing field as a social space characterised by conscious and unconscious manoeuvres, where actors develop strategies to develop and maintain the accumulation of capital in order to improve and maintain positions, status and power. The traditionalist and middle classes still have particular forms of capital that eases their entry into this field where they learn, accommodate and negotiate the new rules of the game (Bourdieu, 1984) through immersion in the specific context and engagement with social media networks.

Social media and associated platforms are used instrumentally to cultivate, demonstrate and maintain social status, positioning and identity construction (Katz \& Gurevitch, 1974; Ruggiero, 2000). There seems to be little evidence to suggest that social media significantly increases participation from outside the contextual community. This research has indicated 
that social involvement in this climbing context is concerned with maintaining, developing and acquiring social networks, cultivation of capitals, habitus and social positioning. Climbers in this study have indicated that their climbing relationships are separate from other social networks and are based around task and competence based considerations. These relationships are generally substantive in that they are usually long-term established partnerships formed between people who have similar social capitals and credentials.

Indoor climbing venues have become sites which facilitate the integration of other social activities such as families, careers and leisure as an extension of the middle class lifestyle and constitute diverse networks of resources and interrelated activities (Wheaton, 2004, 2010). These networks can be maintained and expanded through social media from outside the specific context. Increased access and participation, across age and gender, seems to be a reflection of the broadening of the middle class social positioning through horizontal expansion rather than the vertical integration and inclusion of other groups and individuals.

\section{References}

Adler, P. S., and S. W. Kwon. 2002. Social capital prospects for a new concept. Academy of Management Review, 27(1): 17-40.

Beedie, P. 2008. 'Legislators and Interpreters'. In Philosophy, Risk and Adventure Sports, ed. M.McNamee, 25-42. New York: Routledge.

Blackshaw, T.and J. Long. 2005. What's the big idea a critical exploration of the concept of social capital and its incorporation into leisure policy discourse? Leisure Studies, 24: 239258.doi:10.1080/0261436052000327285

Bogardus, L.M., 2011. The bolt wars: A social worlds perspective on rock climbing and intragroup conflict. Journal of Contemporary Ethnography, p.0891241611426429.

Bourdieu, P. 1984. Distinction: A social critique of the judgement of taste. London: Routledge.

Bourdieu, P. 1986. The forms of capital. In J. G. Richardson (Ed.), Handbook of theory and research sociology of education, 241-258. New York, NY: Greenwood Press.

Bourdieu, P. and L. Wacquant. 1992. An invitation to reflexive sociology. Oxford, UK: Polity Press. 
Bourdieu, P. 1990. Logic of practice. Oxford: Polity Press.

Bourdieu, P. 2001. Masculine domination. Stanford, CA: Stanford University Press.

Bourdieu, P. 1999. The weight of the world social suffering in contemporary society. Cambridge,MA: Polity Press.

Breivik, G. 2010. Trends in adventure sports in a post-modern society. Sport in Society, 13: 260-273. doi:10.1080/17430430903522970

Brown, D. 2006. Pierre Bourdieu's "Masculine Domination" Thesis and the gendered body in sport and physical culture. Sociology of Sport Journal, Human Kinetics, Inc. 23: 162-188.

Brown, D. 2009. The big drum: The mutability of a sporting habitus: Mountaineering in Scotland as a case study. International Review for the Sociology of Sport, 44: 315330.doi:10.1177/1012690209343627.

Bunn, M. (2015). 'I'm gonna do this over and over and over forever!': Overlapping fields and climbing practice. International Review for the Sociology of Sport, 1012690215609785.

Chisholm, D. 2000. Climbing like a girl: An exemplary adventure in feminist phenomenology. Hypatia, 23(1), 9-40.

Coalter, F. 2007. Sports clubs, social capital and social regeneration ill-defined interventions with hard to follow outcomes. Sport in Society, 10, 537-559.

doi:10.1080/17430430701388723

Coleman, J. S. 1990. Foundations of social theory. Cambridge, MA: The Belknap Press of HarvardUniversity Press.

Dilley E.R., and S.J. Scranton. 2010. Women climbing and serious leisure 29:2, 125-141.

Deem, R.1986. All work and no play? The sociology of women and leisure. Milton Keynes: Open University Press

Donath, J., and D. Boyd. 2004. Public displays of connection. BT Technology Journal, 22, 71-82.

Donnelly, M.2006. Studying extreme sports beyond the core participants. Journal of Sport and Social Issues. 30(2): pp 219-224.

Dowling Naess, F. J.1996. Life events and curriculum change: the life history of a Norwegian physical educator. European Physical Education Review (2): 41-53. doi:10.1177/1356336X9600200105

Feld, S. 1981. The focused organization of social ties. American Journal of Sociology 86(5): 1015-1035.

Fletcher, R. 2008. Living on the edge: The appeal of risk sports for the professional middle class.Sociology of Sport Journal,( 25): 310-330.

Glaser, B., and A.L. Strauss.1967. The discovery of grounded theory: Strategies for qualitative research. Chicago, IL: Aldine.

Gilbert, E., and K. Karahalios. 2009. Predicting tie strength with social media. In Proceedings of the SIGCHI Conference on Human Factors in Computing Systems: 211-220. ACM.

Granovetter, M. 1973. The strength of weak ties. American Journal of Sociology 78(6): $1360-1380$. 
Green, E. 1998."'Women doing friendship':An analysis of women's leisure as a site for identity construction, empowerment and resistance." Leisure Studies 17:171-185.

Green, E., Hebron, S., and D. Woodward.1990. Women's leisure, what leisure. London: Macmillan.

Grenfell, M. 2008. Pierre Bourdieu; key concepts. London: Acumen Press.

Hammersley, M., and P. Atkinson.1983. Ethnography: Principles in Practice. London: Tavistock.

Hampton, K. N., Lee, C. J., and E.J. Her. 2011. How new media affords network diversity: Direct and mediated access to social capital through participation in local social settings. New Media \& Society, 1461444810390342.

Hartmann, D., and C. Kwauk. 2011. Sport and development an overview critique and reconstruction. Journal of Sport and Social Issues 35: 284-305. doi:10.1177/01937235114 16986

Heywood, I.(2006. Climbing monsters: Excess and restraint in contemporary rock climbing. Leisure studies, 25(4), 455-467.

Holland-Smith, D., \& Olivier, S. 2013. 'You don't understand us!' An inside perspective on adventure climbing. Sport in Society, 16, 1091-1104. doi:10.1080/17430437.2013.790889

Holland-Smith, D. 2016. 'All the places we were not supposed to go':

a case study of formative class and gender habitus in adventure climbing, Sport, Education and Society, DOI: 10.1080/13573322.2014.994177

Honea, J. C. 2004. Youth cultures and consumerism: alternative sport and possibilities for resistance. Paper presented at The Annual Meeting of the American Sociological Association San Francisco.

Howitt, K. 2004. 'The code of practice for Scottish sport climbing'. The Scottish Mountaineer, 25, 13.

Humberstone, B. 2011. Embodiment and social and environmental action in nature-based sport:

Spiritual spaces. Leisure Studies, 30, 495-4512. doi:10.1080/02614367.2011.602421

Jones, R.L., Armour, K.M., and P. Potrac. 2003. Constructing expert knowledge: A case study of a top-level professional soccer coach. Sport Education and Society, 8, 213-229. doi:10.1080/13573320309254

Katz, E., and M. Gurevitch. 1974. Utilization of mass communication by the individual. In J. G. Blumler \& E. Katz (Eds.), The uses of mass communication (pp. 19-32). London: Faber.

Kay, T., and S. Bradbury. 200). Youth sport volunteering developing social capital. Sport, Education and Society, 14, 121-140. doi:10.1080/13573320802615288

Kelly, L. 2011. Social inclusion through sports based interventions. Critical Social Policy, 31, 126-150. doi:10.1177/0261018310385442

Kenski, K., and N.J. Stroud.2006. Connections between Internet use and political efficacy, knowledge, and participation. Journal of Broadcasting \& Electronic Media, 50(2): 173-192.

Lewis, N. 2000. The climbing body, nature and the experience of modernity.Body \& society, 6(3-4), 58-80. 
Li, Y.2015. Social Capital in Sociological Research conceptual rigour and empirical application in: Li, Y (ed) Handbook of Research Methods and Applications in Social Capital. Edward Elgar Publishing Ltd. Cheltnam, Uk. 1-12.

Lofland, L. 1998. The Public Realm. New York: Aldine de Gruyter.

Ottesen, L., Jeppesen, R. S., and B.R. Krustrup. 2010. The development of social capital through football and running: Studying an intervention program for inactive women.

Scandinavian Journal of Medicine \& Science in Sports 20: 118-131. doi:10.1111/j.16000838.2010.01123.x

Paik, A., and L. Navarre-Jackson.2011. Social networks recruitment and volunteering are social capital effects conditional on recruitment. Non-profit and Voluntary Sector Quarterly, 40: 476-496.doi: 10.1177/0899764009354647

Plate, K. 2007. 'Rock Climbing is a Masculine Sport? Understanding the Complex Gendered Subcultures of Rock Climbing.' Special issue of Sheffield. Sheffield Online Papers in Social Research: 1-14.

Putnam, R. D. 1993. The prosperous community: Social capital and public life. The American Prospect 4:11-18.

Putnam, R. D. 1995a. Tuning in, tuning out: The strange disappearance of social capital in America. Political Science and Politics, 28, 664-683. doi:10.1017/S1049096500058856

Putnam, R. D. 1995b. Bowling alone America's declining social capital. Journal of Democracy 6(1): 65-78. doi:10.1353/jod.1995.0002

Putnam, R. D. 2004. Bowling together. OECD Observer. Retrieved July 28, 2008, fromhttp://www.oecdobserver.org/news/fullstory.php/aid/1215/Bowling_together.html.

Rinehart, R. E. 2000. 'Emerging Arriving Sports': Alternative sports, inside and out. (Albany: State University of New York Press).

Roberts, B.2002. Biographical Research. Open University Press. Buckingham and Philadelphia.

Robinson, V.2004. 'Taking Risks: Identity, Masculinities and Rock Climbing'. In Understanding Lifestyle

Sports, ed. B. Wheaton, 113-30. London: Routledge,

Robinson, V.2008. Everyday Masculinities and Extreme Sports: Male Identity and Rock Climbing. New

York: Berg.

Ruggiero, T. 2000. Uses and gratifications theory in the 21st century. Mass Communication \& Society, 3(1): 3-37.

Salome, L. (2010). Constructing authenticity in contemporary consumer culture: the case of lifestyle sports. European Journal for Sport and Society. 7(1): 69-87.

Salome, L. and M. Van Bottenburg. 2012. Are they all daredevils? Introducing a participation typology for the consumption of lifestyle sports in different settings. European Sport Management Quarterly. 12(1): 19-42.

Scottish Mountaineering Trust. 2013. Scottish sports climbs, Scottish mountaineering club climbers' guide. Cardee. 
Scraton, S. 1994. The changing world of women and leisure: Feminism, 'postfeminism' and leisure. Leisure Studies, 13(4):249-261.

Skinner, J., Zakus, D., \& Cowell, J. 2008. Development through Sport building social capital in disadvantaged communities. Sport Management Review, 11: 253-275.

doi:10.1016/S1441-3523(08)70112-8

Sparkes, A. C.1998. 'Validity in qualitative enquiry and the problem with criteria: 'Implications for sport psychology' The sport Psychologist, 12, 63-86.

Stempel, C. 2006. Gender social class and the sporting capital economic capital nexus. Sociology of Sport Journal, 23: 273-292.

Talbot, M. 1988. Beating them at their own game? Women's sport involvement. In E. Wimbush \& M. Talbot (Eds.), Relative freedoms: Women and leisure (pp. 102-114).

Thorpe, H. 2005. Jibbing the gender order: Females in the snowboarding culture. Sport in Society, 8(1), 76-100. doi:10.1080/1743043052000316632

Tomlinson, A., N.Ravenscroft., B. Wheaton., and P. Gilchris .2000.. Lifestyle Sports and National Sport Policy': An Agenda for Research. Sport England.

Tenni, C., A. Smyth., and C. Boucher. 2003. The researcher as autobiographer: Analysing data written about oneself. The Qualitative Report, 8(1).

Tufford, L., and P. Newman. 2010. Bracketing in qualitative research. Qualitative Social Work, 11, 80-96. Doi: 10.1177/1473325010368316

Van Manen, M. 1997. Researching lived experience: Human science for an action sensitive pedagogy. London, Ontario: Althouse Press.

Valenzuela, S., N. Park., and K. Kee. 2009. Is There Social Capital in a Social Network Site? Facebook Use and College Students' Life Satisfaction, Trust, and Participation1. JCMC, 14(4): 875-901.

Wasko, M.M., and S. Faraj. 2000. Social Capital \& Knowledge Contribution. MIS Quarterly 29 (1):35-57.

Wellman, B. 2001. Physical place and cyber-place: Changing portals and the rise of networked individualism. International Journal for Urban and Regional Research 25(2): $227-$ 252.

West, A., \& Allin, L. 2010. Chancing your arm: The meaning of risk in rock climbing. Sport inSociety, 13, 234-248.

Wheaton. B. 2004. Understanding Lifestyle Sports: Consumption, Identity and Difference. London: Routledge.

Wheaton, B. 2010. Introducing the consumption and representation of lifestyle sports. Sport in Society: Cultures, Commerce, Media, Politics, 13, (7/8): 1057-1081.

Whittaker, C.G., and D. David Holland-Smith. 2014. Exposing the dark side, an exploration of the influence social capital has upon parental sports volunteers, Sport, Education and Society, doi: 10.1080/13573322.2014.923832

Williams, D. 2006. On and off the 'net: Scales for social capital in an online era. JCMC, 11(2). 
Williams, R. 1977. Marxism and literature (Vol. 1). Oxford University Press. 